\title{
Treatment of spondylodiscitis after rectopexy: surgery is always required-Fauheron JL, Trilling B
}

\author{
A. Pasquer ${ }^{1}$
}

Received: 12 April 2017/ Accepted: 17 April 2017/Published online: 15 May 2017

(C) Springer International Publishing AG 2017

We read with interest the article by Faucheron and Trilling [1]. We would like to comment on some of the questions raised:

(1) The surgeon who operated the patient was an expert urologist from another surgical team. As stated by the authors, spondylodiscitis after rectopexy is very rare in experienced hands. This case was the only one in our extended cohort including 731 consecutive Orr-Loygue procedures that were performed by the same surgeon.

(2) We agree with the fact that multimodal diagnostic imaging was excessive. Indeed, as shown in our figure, the computed tomography scan made possible the diagnosis [2]. The bone scintigraphy and magnetic resonance imaging did not delay antibiotic treatment as we started it immediately.

(3) Laparoscopy could have been attempted, but in a context of uncontrolled sepsis, an open approach was preferred used because it permitted more rapid intervention.

(4) We agree that the rectal perforation was too large and the local peritonitis too severe for conservative treatment.

\section{Compliance with ethical standards}

Conflict of interest The authors declare that they have no conflict of interest.

Ethical approval All procedures performed in studies involving human participants were in accordance with ethical standards of the institutional research committee and with the 1964 Helsinki Declaration and its later amendments or comparable ethical standards.

Informed consent Informed consent was obtained from the patient.

\section{References}

1. Faucheron L, Trilling B (2017) Treatment of spondylodiscitis after rectopexy: surgery is always required. Tech Coloproctol. doi:10. 1007/s10151-017-1606-Z

2. Pasquer A, Djeudji F, Pechoux A, Barth X (2017) Spondylodiscitis after rectopexy: diagnostic of a rare complication. Tech Coloproctol 21:63-64
A. Pasquer

arnaud.pasquer@chu-lyon.fr

1 Department of Digestive and Colorectal Surgery, Edouard Herriot University Hospital, 5 Place d'Arsonval, 69003 Lyon, France 